\title{
Digital Therapeutics Hold a Promising Prospect in the Healthcare Sector - Explore How
}

\author{
Ashish Gujrathi \\ Allied Market Research, Viman Nagar Pune Sainik Nagar, Somnath Nagar, Wadgaon Sheri, Pune.
}

Corresponding Author: Ashish Gujrathi. Allied Market Research, Viman Nagar Pune Sainik Nagar, Somnath Nagar, Wadgaon Sheri, Pune.

Received date: August 20, 2021; Accepted date: August 27, 2021; Published date: September 06, 2021

Citation: Ashish Gujrathi. (2021) Digital Therapeutics Hold a Promising Prospect in the Healthcare Sector - Explore How. Clinical Research and Clinical Trials. 4(3); DOI: 10.31579/2693-4779/060

Copyright: (c) 2021 Ashish Gujrathi, This is an open access article distributed under the Creative Commons Attribution License, which permits unrestricted use, distribution, and reproduction in any medium, provided the original work is properly cited.

The treatments of several diseases are evolving continuously towards a digital future indeed. Digital therapeutics use digital technologies to prevent, manage, or cure physical and mental health conditions. In the past ten years, the outcomes from digital therapeutics in a broad range of symptoms, such as cancer, ADHD, asthma, mental disorders, and insomnia have improved to a great extent, thereby making it more popular around the world.

As digital therapeutics are referred as medical appliances, the United States Food and Drug Administration (FDA) offers an oversight of protection and effectiveness. The Digital Software PreCertification program of FDA provides certifications and a streamlined process for product approvals to those companies that have already had a robust culture of quality and organizational excellence.

A lot of products, now-a-days, are used with digital therapies in order to give a sense of variety of approaches to healthcare problems, for example, video games are used to treat mental and behavioral health issues, few smartphone apps are used to perform electrocardiograms, and music therapy, sensors \& artificial intelligence is used to cure stroke patients or people with neurological disorders.

Moreover, the global tech companies are amalgamating their data assembling and analytic competencies with their vast scales in order to evolve into a new healthcare infrastructure. For example -

$\checkmark$ Amazon's Alexa can determine few health issues through simple voice commands.

$\checkmark$ Google is registering AI into so many healthcare areas.

$\checkmark$ Apple, at the same time, is enabling patients to view all their data on their phones by making advancements of wearable devices that allow for continuous monitoring and integration of electronic health records.

Successful digital therapeutic companies possess big data and advanced analytics, hardware engineering, human centered product design, and flexible business models. That is why, pharmaceutical companies are looking for partnerships with digital therapeutic companies so that they can gain access to new technologies. Digital therapeutic companies will also benefit from this partnership as they will have a greater and wider scale of patients to serve for.

According to a report published by Allied Market Research, the digital therapeutic market size is projected to reach $\$ 13.80$ billion with a considerable CAGR from 2019-2027. Here, it's worth mentioning that, the outbreak of the COVID-19 pandemic has positively impacted the market by creating awareness regarding the importance of digital health.

At the same time, a wide consumer interest in healthier living and increase in adoption of smartphones \& tablets have influenced the digital therapeutic companies to launch products through direct consumer channels. The Kardia Mobile System and Snore Lab are two different mobile applications launched for monitoring meditation and sleep.

Furthermore, digital therapeutic tools must be integrated carefully into clinician's workflows in order to avoid significant adoption barriers. A company, Omeda Health that provides digital therapies used by many healthcare providers to cure chronic diseases, has recently signed a partnership with the American Medical Association. This in turn, helped Omega Health to understand the integration process of therapies ideally with both clinical workflows and electronic records. 


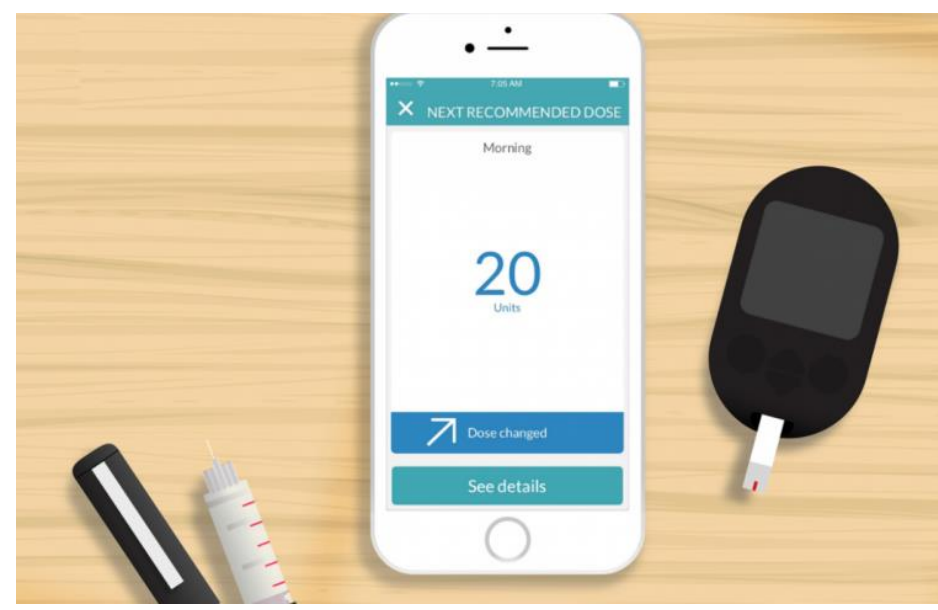

This work is licensed under Creative Commons Attribution 4.0 License

\section{To Submit Your Article Click Here: Submit Manuscript}

DOI: $10.31579 / 2693-4779 / 060$
Ready to submit your research? Choose Auctores and benefit from:

$>$ fast, convenient online submission

$>\quad$ rigorous peer review by experienced research in your field

$>$ rapid publication on acceptance

$>$ authors retain copyrights

$>$ unique DOI for all articles

$>$ immediate, unrestricted online access

At Auctores, research is always in progress.

Learn more https://auctoresonline.org/journals/chinese-clinicalresearch-and-trials- 